\title{
Corrigendum to "Fatty Acid Profiles of Stipe and Blade from the Norwegian Brown Macroalgae Laminaria Hyperborea with Special Reference to Acyl Glycerides, Polar Lipids, and Free Fatty Acids"
}

\author{
Lena Foseid $(\mathbb{D}$, Hanne Devle $(\mathbb{D}$, Yngve Stenstrøm, Carl Fredrik Naess-Andresen $(\mathbb{D}$, \\ and Dag Ekeberg $\mathbb{D}$
}

Faculty of Chemistry, Biotechnology and Food Science, Norwegian University of Life Sciences, P.O. Box 5003, 1432 Ås, Norway

Correspondence should be addressed to Hanne Devle; hanne.devle@nmbu.no

Received 16 December 2020; Accepted 16 December 2020; Published 16 January 2021

Copyright (c) 2021 Lena Foseid et al. This is an open access article distributed under the Creative Commons Attribution License, which permits unrestricted use, distribution, and reproduction in any medium, provided the original work is properly cited.

In the article titled "Fatty Acid Profiles of Stipe and Blade from the Norwegian Brown Macroalgae Laminaria Hyperborea with Special Reference to Acyl Glycerides, Polar Lipids, and Free Fatty Acids" [1], the authors identified a systematic error in the calculations of the fatty acid contents. This error impacts the values in the text as well as both the tables and the figures. Therefore, while the conclusions of the article are not affected, the reported results are slightly altered. The authors apologize for this error, and the corrected version of the article is shown below:

A thorough analysis of the fatty acid profiles of stipe and blade from the kelp species Laminaria hyperborea is presented. Lipid extracts were fractionated into neutral lipids, free fatty acids, and polar lipids, prior to derivatization and GC-MS analysis. A total of 42 fatty acids were identified and quantified, including the $n-3$ fatty acids, $\alpha$-linolenic acid, stearidonic acid, and eicosapentaenoic acid. The fatty acid amounts are higher in blade than in stipe $(6.10 \mathrm{mg} / \mathrm{g}$ dry weight and $2.00 \mathrm{mg} / \mathrm{g}$ dry weight, respectively). The highest amounts of $n-3$ fatty acids are found within the neutral lipid fractions with $563.4 \mu \mathrm{g} / \mathrm{g}$ dry weight and $97.4 \mu \mathrm{g} / \mathrm{g}$ dry weight for blade and stipe, respectively. The amounts of polyunsaturated fatty acids are 3.3 times higher in blade than stipe. The blade had the highest PUFA/SFA ratio compared to stipe (1.18 versus 1.00$)$ and the lowest $n-6 / n-3$ ratio (0.8 versus 3.6). This study highlights the compositional differences between the lipid fractions of stipe and blade from L. hyperborea. The amount of polyunsaturated fatty acids compared to saturated and monounsaturated fatty acids is known to influence human health. In the pharmaceutical, food, and feed industries, this can be of importance for production of different health products.

\section{Introduction}

The increase in the world population and lack of sufficient food begs for new sources of food and feed. As much as $60 \%$ of the world food energy intake is provided by the cereals wheat, rice, and corn [2], these cereals, while high in metabolizable energy and carbohydrates, have small amounts of important nutrients such as proteins, minerals, vitamins (especially A and C), and fatty acids, especially long chained polyunsaturated $n-3$ fatty acids [3-5]. A promising supplement for food and feed is a better utilization of marine resources. World production and harvesting of micro- and macroalgae have doubled from 2004 to 2014 [6]. Still, 97\% of the production and harvesting is found in Asia [6]; thus, there is a large potential for expansion in other parts of the world. Macroalgae is a diverse group of marine plants, informally divided into three groups: rhodophyta (red algae), chlorophyta (green algae), and phaeophyta (brown algae). Use of seaweed as feed, food, and fertilizers in times of food shortage was common in northern Europe from around the $10^{\text {th }}$ century and up until about middle of the $18^{\text {th }}$ century 
[7]. At present time in Scandinavia and other Western countries, the utilization of seaweeds is limited to industrial products such as alginate, agar, carrageenan and thickeners, and only scarcely used in food and feed industries. Biomarine processing industries have great potential in coastal regions. Norway is particularly privileged due to the long coastline combined with the presence of nutritious ocean currents (North Atlantic Drift and Norwegian Coastal Current), which ensures a good climate for growth of marine flora and fauna.

Seaweed has for many years been thought to have a positive effect on human health, and consumption of these marine plants has been linked to a lower incidence of cancer, hyperlipidemia, and coronary heart disease [8]. They are also reported to possess antimicrobial, antiviral, anti-inflammatory, and immunotropic properties [9]. Many of the reported medicinal effects of marine algae have not been confirmed, but Brown et al. and Stein \& Borden have published comprehensive reviews on this topic $[8,10]$. Lipid profiles and compositions can be of importance for human health and for commercial application [11-13]. Eukaryotic algae contain a diverse composition of acyl lipids and their fatty acids; albeit, the number of algae which have been comprehensively studied are relatively few [12]. Lipids in macroalgae can be divided into neutral lipids that include monoglycerides, diglycerides, triglycerides, sterols, and polar lipids that include glycolipids, phospholipids, and betaine lipids [11, $12,14]$. An important nutritional benefit of marine macroalgae is attributed to the high level of polyunsaturated fatty acids (PUFAs), especially $n-3$ and $n-6$ fatty acids [15]. A diet with a low $n-6 / n-3$ ratio is reported to have suppressive effects on cardiovascular diseases, cancer, and inflammatory and autoimmune diseases [16]. With a global decline in fish stocks, seaweed may be a good option for an alternative and sustainable source of $n-3$ PUFAs [8]. Previous studies regarding fatty acids in brown macroalgae have had a nutritional or pharmaceutical focus. The fatty acid content has only been determined as one among several parameters, resulting in limited fatty acid profiles [17-21]. More extensive FA profiling has been done on certain species of brown macroalgae [9, 22-24]. Little is however known about fatty acid compositions of individual lipid classes of marine macrophytes in general [9]. The brown macroalgae Laminaria hyperborea, a common species of kelp found in the northern Atlantic, has only previously been characterized with regard to fatty acids in three studies $[7,13,25]$, all presenting limited profiles identifying no more than nine fatty acids. The within-plant fatty acid distribution for this species has previously only been reported by Schmid and Stengel [25] with Laminaria hyperborea harvested on the west coast of Ireland. Variations in distribution of fatty acids between different parts of the seaweed depend on the morphology of the species as well as its physiological and ecological circumstances [26].

Before considering the marine algae as a food source, it is important to assess its nutritional value. In this context, the aim of this study has been to provide a thorough analysis of the fatty acid profiles in stipe and blade from the macroalgae L. hyperborea. In this study, the lipids were fractionated into free fatty acids (FFAs), acyl glycerides (neutral lipids, NLs), and polar lipids (PLs) by using solid phase extraction. The fatty acids from each class were identified and quantified by GC-MS.

\section{Material and Methods}

Chloroform and hexane were of Chromasolv ${ }^{\circledR}$ quality, heptane, diethyl ether, methanol, and $\mathrm{NaCl}$ puriss pa. quality, all from Sigma-Aldrich (St. Louis, MO, USA). The acetic acid was from Honeywell Riedel-de Haen (Seelze, Germany).

2.1. Standards. A fatty acid methyl ester (FAME) mix with 37 components (Food Industry Fame MIX, Restek, Bellefonte, PA, USA) was used for identification of the FAMEs. A 21 component FAME mix (Qualmix PUFA Fish M, Methyl Esters (Menhaden Oil), Larodan AB, Solna, Sweden) was used for identification of all-cis-6,9,12,15-octadecatetraenoic acid methyl ester, all-cis-8,11,14,17-eicosatetraenoic acid methyl ester, and all-cis-7,10,13,16,19-docosapentaenoic acid methyl ester. In addition, the following individual FAME standards were used: nonanoic acid methyl ester (SigmaAldrich, St. Louis, MO, USA), 13-methyltetradecanoic acid methyl ester, trans-9-tetradecenoic acid methyl ester, cis-9heptadecenoic acid methyl ester, cis-13-octadecenoic acid methyl ester, cis-9-eicosenoic acid methyl ester, and hexacosanoic acid methyl ester (all from Larodan AB, Solna, Sweden). Three internal standards were used $(10 \mathrm{mg} / \mathrm{mL}$, dissolved in $\mathrm{CHCl}_{3}$ ), one for each lipid fraction, 1,2-dinonadecanoyl-sn-Glycero-3-phosphatidylcholine for the PL fractions, nonadecanoic acid for the FFA fractions, and trinonadecanoin for the NL fractions (all from Larodan $\mathrm{AB}$, Solna, Sweden). Nonadecanoic acid methyl ester (Larodan $\mathrm{AB}$, Solna, Sweden) was added to the 37 components FAME mix for retention time identification, since C19:0 was used as internal standard in the samples.

2.2. Pretreatment of L. Hyperborea. L. hyperborea was provided and identified by FMC BioPolymer AS. It was harvested off the west coast of Norway, outside Sør-Trøndelag County Municipality in October 2015. On board, the trawler L. hyperborea was rinsed, crude-cut, and preserved with formalin manually. The holdfast was discarded. Once off, the trawler stipe and blade were vacuum packed separately. When received at the university, stipe and blade were rinsed with water to eliminate contaminants, frozen with liquid $\mathrm{N}_{2}$ (99.999\%, AGA, The Linde Group, Munich, Germany), and freeze-dried (Alpha 2-4 LD plus, Martin Christ Gefriertrocknungsanlagen $\mathrm{GmbH}$, Osterode am Harz, Germany). The freeze-dried material was crushed in a QMM Micro-Mixer and pulverized in a Laboratory Mixer 3100 (Danfoss) by G. A. Lund at Pharmatech AS, Fredrikstad, Norway. The water content of fresh seaweed was measured according to ISO $11465: 1993 /$ Cor $1: 1994$.

2.3. Lipid Extraction. Four sample replicates of both stipe and blade were used, and they were all treated separately during the sample preparation stages. The lipids were extracted with a modified Folch's method [27]. In brief, 5-10 g alga powder was extracted in a separatory funnel with 10 times its volume $\mathrm{CHCl}_{3}: \mathrm{MeOH}(2 / 1)$, and $50 \mu \mathrm{L}$ of each internal standard was 
added with a Hamilton ${ }^{\circledR}$ syringe. To induce phase separation, $0.9 \% \mathrm{NaCl}$ was added after mixing ( 0.2 times the volume of $\mathrm{CHCl}_{3}: \mathrm{MeOH}$ ). After approximately $20 \mathrm{~min}$, the organic phase was transferred to a test tube (Duran ${ }^{\circledR} 20 \times 150 \mathrm{~mm}$, Mainz, Germany). The polar phase was reextracted with $\mathrm{CHCl}_{3}, 30-60 \mathrm{~mL}$ depending on the amount of alga powder. The organic phases of each sample were combined and evaporated with a vacuum evaporator (Q-101, Buchi Labortechnik AG, Flawil, Switzerland) at $40^{\circ} \mathrm{C}$, redissolved in $1.00 \mathrm{~mL}$ chloroform, and transferred to vials for SPE.

A liquid-handling robot (Gilson, GX-271, ASPEC, Middleton, WI, USA) was used to carry out the SPE procedure. The method used was based on previous work by Pinkart et al. 1998 and Ruiz et al. 2004 [28, 29]. Aminopropyl-modified silica phase SPE columns, $500 \mathrm{mg}$, $3 \mathrm{~mL}$, (Chromabond, Macherey-Nagel, Düren, Germany) were conditioned with $7.5 \mathrm{~mL}$ hexane before $500 \mu \mathrm{L}$ of sample was applied. The NLs (mono-, di-, and triglycerides) were eluted with $5 \mathrm{~mL}$ chloroform, then the FFAs with $5 \mathrm{~mL}$ diethyl ether: acetic acid $(98: 2 \mathrm{v} / \mathrm{v})$, and lastly, the PLs with $5 \mathrm{~mL}$ methanol. The possibility of crosscontaminations between any of the three classes was checked by performing tests with standards for each lipid class. The recovery was $90 \%$ or higher. The eluates were transferred to culture tubes (Duran $12 \times 100 \mathrm{~mm}$, Mainz, Germany) and evaporated under $\mathrm{N}_{2}$ (g) at $40^{\circ} \mathrm{C}$.

2.4. Formation of FAMEs. For formation of FAMEs, the NL and PL fractions were redissolved in $2 \mathrm{~mL}$ of heptane, before addition of $1.5 \mathrm{~mL}$ of $3.3 \mathrm{mg} / \mathrm{mL}$ sodium methoxide. The sodium methoxide solution was made by dissolving metallic sodium (purum, Merck, Darmstadt, Germany) in methanol to a concentration of $3.3 \mathrm{mg} / \mathrm{mL}$. The culture tubes were then shaken horizontally for $30 \mathrm{~min}$ at $350 \mathrm{rpm}$ (Biosan Ltd, PSU10i, Riga, Latvia) and left to settle vertically for $10 \mathrm{~min}$ before the heptane phases were transferred to vials for storage at $-20^{\circ} \mathrm{C}$ prior to GC-MS analysis. The FFA fractions were redissolved in $1 \mathrm{~mL} \mathrm{BF}_{3}-\mathrm{MeOH}$ (14\%, Sigma-Aldrich, St.Louis, MO, USA). The samples were heated for $5 \mathrm{~min}$ at $70^{\circ} \mathrm{C}$ in a water bath. After heating, $1 \mathrm{~mL}$ heptane was added to each sample tube before mixing on a vortex mixer. The heptane phases were transferred to vials and stored at $-20^{\circ} \mathrm{C}$ prior to analysis by GC-MS.

2.5. Analysis of FAMEs by GC-MS. The analysis of the FAMEs was based on a previously published method [30]. Shortly, the analysis were carried out on an Agilent 6890 Series Gas Chromatograph (GC; Agilent Technology, Wilmington, DE, USA) in combination with an Autospec Ultima mass spectrometer (MS; Micromass Ltd., Manchester, England) using an EI ion source. The GC was equipped with a CTC PAL Autosampler (CTC Analytics, AG, Zwingen, Switzerland). Separation was carried out on a $60 \mathrm{~m}$ Restek column ( $\mathrm{Rtx}^{\circledR}{ }^{\circledR} 2330$ ) with $0.25 \mathrm{~mm}$ I.D. and a $0.2 \mu \mathrm{m}$ film thickness of fused silica $90 \%$ biscyanopropyl $/ 10 \%$ phenylcyanopropyl polysiloxane stationary phase (Restek Corporation, Bellefonte, PA, USA). Carrier gas helium (99.99990\%, from Yara, Rjukan, Norway) was used at $1 \mathrm{~mL} / \mathrm{min}$ constant flow. The EI ion source was used in positive mode, producing
$70 \mathrm{eV}$ electrons at $250^{\circ} \mathrm{C}$. The MS was scanned in the range $40-600 \mathrm{~m} / z$ with $0.3 \mathrm{~s}$ scan time, $0.2 \mathrm{~s}$ inter scan delay, and $0.5 \mathrm{~s}$ cycle time. The transfer line temperature was set at $270^{\circ} \mathrm{C}$. The resolution was 1000 .

A split ratio of $1 / 10$ was used with injections of $1.0 \mu \mathrm{L}$ sample. Two injections parallels were used for each sample replicate. Identification of fatty acids was performed by comparing retention times with standards as well as MS library searches. MassLynx version 4.0 (Waters, Milford, MA, USA) and NIST 2014 Mass Spectral Library (Gaithersburg, MD, USA) were used. Relative response factors previously determined by Devle et al. [30] were employed for quantitative determination. The resulting amounts are given in $\mu \mathrm{g} / \mathrm{g}$ dry weight (DW). The GC oven had a start temperature of $65^{\circ} \mathrm{C}$, held for $3 \mathrm{~min}$, the temperature was then raised to $150^{\circ} \mathrm{C}\left(40^{\circ} \mathrm{C} / \mathrm{min}\right)$, held for $13 \mathrm{~min}$, before being increased to $151^{\circ} \mathrm{C}\left(2^{\circ} \mathrm{C} / \mathrm{min}\right)$, and held for $20 \mathrm{~min}$, with a slow increase to $230^{\circ} \mathrm{C}\left(2^{\circ} \mathrm{C} / \mathrm{min}\right)$ and held for $10 \mathrm{~min}$, before a final increase to $240^{\circ} \mathrm{C}\left(50^{\circ} \mathrm{C} / \mathrm{min}\right)$, and the end temperature was held for $3.7 \mathrm{~min}$.

\section{Results and Discussion}

We have identified and quantified 42 different fatty acids in L. hyperborea, as shown in Table 1 . This is a significantly higher number than previously reported by others for this species $[7,13,25]$. Seaweeds usually contain a lipid level of $<1-5 \%[20,22,31]$. The portions of the total lipids that contain molecules with fatty acids depend significantly on species, geographical location, and seasonal changes [13, $19,25,32,33$ ]. In our study, the total FA (TFA) content relative to dry weight in blade and stipe was $0.61 \%$ and $0.20 \%$, respectively. This $3: 1$ ratio between blade and stipe is consistent with Schmid and Stengel [25] findings of within-plant variations for the same species, even though they had twice the TFA content $(0.5 \%$ and $1.5 \%$ in stipe and blade, respectively). The water content was found to be $83.3 \% \pm 0.5$ and $85.6 \% \pm 0.8$ in blade and stipe, respectively. The fatty acid profile was determined for the NL, FFA, and PL fractions in stipe and blade separately. For the individual lipid fractions, the \%TFA was the highest in NLs with $49.6 \%$ and $59.1 \%$ in stipe and blade, respectively. The PL fraction for the stipe consisted of $40.5 \%$ TFA versus $25.6 \%$ TFA in blades. The \%TFA for the FFAs ranged from $9.8 \%$ in stipe to $15.4 \%$ in blade. While up to 41 different fatty acids were detected within a lipid fraction, the same 10 fatty acids predominated in all fractions in both stipe and blade. In this group of 10, three FAs were saturated (SFA, C14:0, C16:0 and C18:0), two were monounsaturated (MUFA, C16:1 cis-9, and C18:1 cis-9), and the remaining five were polyunsaturated (PUFA, C18:2 cis-9,12, C18:3 cis-9,12,15, C18:4 cis-6,9,12,15, C20:4 cis-5,8,11,14, and C20:5 cis-5,8,11,14,17).

The predominating fatty acids constitute more than $90 \%$ of the total fatty acid content in all the fractions, as shown in Figure 1. They are found in amounts varying from 0.61 to $1090 \mu \mathrm{g} / \mathrm{g}$ DW (Table 1). A fatty acid was classified as predominating if it was above $2 \%$ of the total fatty acid content in at least one of the lipid fractions in 
TABLE 1: Fatty acid content in the lipid fractions (mean $\pm S D, \mu \mathrm{g} / \mathrm{g} \mathrm{DW})$ of stipe and blade from $L$. hyperborea $(n=4$, two injection parallels for each of these four sampling events).

\begin{tabular}{|c|c|c|c|c|c|c|c|}
\hline \multirow{2}{*}{ Fatty acid } & & \multicolumn{3}{|c|}{ Stipe } & \multicolumn{3}{|c|}{ Blade } \\
\hline & & NL & FFA & PL & $\mathrm{NL}$ & FFA & PL \\
\hline C7:0 5 methyl $^{\mathrm{a}}$ & & $0.61 \pm 0.04$ & n.d. & n.d. & $0.23 \pm 0.01$ & n.d. & n.d. \\
\hline $\mathrm{C} 8: 0$ & & $0.68 \pm 0.05$ & $0.34 \pm 0.02$ & n.d. & $2.48 \pm 0.29$ & $0.31 \pm 0.01$ & n.d. \\
\hline C9: 0 & & n.d. & $0.22 \pm 0.03$ & n.d. & n.d. & $0.34 \pm 0.02$ & n.d. \\
\hline $\mathrm{C} 10: 0$ & & $0.42 \pm 0.03$ & n.d. & n.d. & $2.76 \pm 0.35$ & $0.22 \pm 0.03$ & n.d. \\
\hline $\mathrm{C} 12: 0$ & & $0.34 \pm 0.06$ & $1.11 \pm 0.15$ & $0.06 \pm 0.01$ & $0.47 \pm 0.02$ & $1.93 \pm 0.09$ & $0.04 \pm<0.00$ \\
\hline $\mathrm{C} 13: 0$ & & n.d. & $0.14 \pm 0.01$ & n.d. & $0.12 \pm 0.01$ & $0.69 \pm 0.02$ & $0.04 \pm<0.00$ \\
\hline $\mathrm{C} 14: 0$ & & $74.33 \pm 1.32$ & $16.79 \pm 0.60$ & $152.06 \pm 5.54$ & $164.25 \pm 3.41$ & $72.21 \pm 3.31$ & $174.39 \pm 3.13$ \\
\hline C14:0 13 methyl & & n.d. & $0.27 \pm 0.04$ & n.d. & n.d. & $0.32 \pm 0.01$ & n.d. \\
\hline C14: 1 trans-9 & & n.d. & $0.15 \pm 0.01$ & n.d. & n.d. & $1.43 \pm 0.09$ & n.d. \\
\hline $\mathrm{C} 14: 1$ cis-9 & & $0.65 \pm 0.03$ & $0.10 \pm 0.01$ & $0.15 \pm 0.02$ & $1.78 \pm 0.02$ & $0.35 \pm 0.01$ & $0.21 \pm 0.01$ \\
\hline $\mathrm{C} 15: 0$ & & $0.74 \pm 0.04$ & $0.81 \pm 0.04$ & $1.49 \pm 0.02$ & $6.80 \pm 0.14$ & $5.20 \pm 0.15$ & $6.18 \pm 0.08$ \\
\hline $\mathrm{C} 16: 0$ & & $134.62 \pm 4.19$ & $70.62 \pm 2.65$ & $173.40 \pm 4.33$ & $741.81 \pm 14.71$ & $256.99 \pm 11.23$ & $261.56 \pm 3.38$ \\
\hline $\mathrm{C} 16: 1^{\mathrm{b}}$ & & n.d. & n.d. & n.d. & $0.63 \pm 0.08$ & $1.12 \pm 0.03$ & $0.40 \pm 0.01$ \\
\hline $\mathrm{C} 16: 1^{\mathrm{b}}$ & & n.d. & $0.45 \pm 0.03$ & $0.23 \pm 0.03$ & $1.83 \pm 0.08$ & $2.35 \pm 0.08$ & $0.66 \pm 0.01$ \\
\hline C16: 1 cis-9 & & $61.31 \pm 2.09$ & $12.26 \pm 0.18$ & $33.95 \pm 0.64$ & $146.88 \pm 1.58$ & $63.23 \pm 1.94$ & $65.17 \pm 0.71$ \\
\hline $\mathrm{C} 17: 0$ & & $0.28 \pm 0.02$ & $0.47 \pm 0.06$ & $0.38 \pm 0.03$ & $5.76 \pm 0.21$ & $1.58 \pm 0.06$ & $1.21 \pm 0.03$ \\
\hline $\mathrm{C} 16: 2$ cis or trans $-7,10^{\mathrm{a}}$ & $\begin{array}{l}(n- \\
6)\end{array}$ & $0.50 \pm 0.03$ & $0.11 \pm 0.02$ & $0.30 \pm 0.04$ & $1.63 \pm 0.05$ & $1.46 \pm 0.04$ & $1.56 \pm 0.03$ \\
\hline $\mathrm{C} 17: 1$ cis-9 & & $0.29 \pm 0.03$ & $0.09 \pm 0.04$ & $0.23 \pm 0.02$ & $3.57 \pm 0.21$ & $1.82 \pm 0.05$ & $1.29 \pm 0.04$ \\
\hline $\mathrm{C} 18: 0$ & & $5.44 \pm 0.26$ & $16.54 \pm 0.68$ & $1.76 \pm 0.06$ & $76.79 \pm 1.84$ & $20.05 \pm 0.72$ & $3.08 \pm 0.04$ \\
\hline $\mathrm{C} 18: 1$ cis-9 & & $212.52 \pm 5.32$ & $44.93 \pm 0.41$ & $288.67 \pm 7.13$ & $1089.76 \pm 27.19$ & $207.93 \pm 5.25$ & $377.59 \pm 8.00$ \\
\hline $\mathrm{C} 18: 1$ cis-11 & & $3.06 \pm 0.28$ & $2.15 \pm 0.04$ & $3.35 \pm 0.16$ & $10.34 \pm 0.19$ & $6.28 \pm 0.15$ & $5.30 \pm 0.10$ \\
\hline C18:2 all-cis-9,12 (LA) ${ }^{\mathrm{c}}$ & $\begin{array}{l}(n \\
-6)\end{array}$ & $40.26 \pm 1.59$ & $2.54 \pm 0.08$ & $33.18 \pm 0.69$ & $165.54 \pm 3.78$ & $21.48 \pm 0.66$ & $60.72 \pm 0.82$ \\
\hline $\mathrm{C} 18: 3$ all-cis-6,9,12 & $\begin{array}{l}(n \\
-6)\end{array}$ & $2.89 \pm 0.19$ & n.d. & $2.45 \pm 0.09$ & $12.55 \pm 0.16$ & $2.82 \pm 0.06$ & $8.37 \pm 0.13$ \\
\hline $\mathrm{C} 20: 0$ & & $6.70 \pm 0.54$ & $1.42 \pm 0.07$ & $1.16 \pm 0.07$ & $49.81 \pm 1.20$ & $10.28 \pm 0.28$ & $3.66 \pm 0.07$ \\
\hline C18:3 all-cis-9,12,15 (ALA) ${ }^{\mathrm{d}}$ & $\begin{array}{l}(n \\
-3)\end{array}$ & $6.54 \pm 0.28$ & $0.61 \pm 0.03$ & $1.61 \pm 0.10$ & $74.77 \pm 1.23$ & $20.57 \pm 0.51$ & $17.17 \pm 0.46$ \\
\hline C20 : 1 cis-9 & & n.d. & $0.41 \pm 0.08$ & $2.53 \pm 0.13$ & $7.86 \pm 0.40$ & $4.34 \pm 0.06$ & $7.40 \pm 0.14$ \\
\hline C20: 1 cis-11 & & n.d. & $0.17 \pm 0.04$ & $0.29 \pm 0.04$ & $0.89 \pm 0.05$ & $0.41 \pm 0.02$ & $0.72 \pm 0.02$ \\
\hline C18 : 4 all-cis-6,9,12,15 (SDA) ${ }^{\mathrm{e}}$ & $\begin{array}{l}(n \\
-3)\end{array}$ & $4.96 \pm 0.23$ & $0.86 \pm 0.03$ & $7.26 \pm 0.16$ & $61.22 \pm 1.15$ & $59.86 \pm 1.33$ & $175.42 \pm 1.87$ \\
\hline $\mathrm{C} 20: 2$ all-cis-11,14 & $\begin{array}{l}(n \\
-6)\end{array}$ & $3.73 \pm 0.35$ & $0.27 \pm 0.05$ & $3.68 \pm 0.14$ & $10.27 \pm 0.33$ & $2.95 \pm 0.12$ & $6.46 \pm 0.13$ \\
\hline $\mathrm{C} 20: 3^{\mathrm{b}}$ & & $1.90 \pm 0.16$ & $0.12 \pm 0.02$ & $0.67 \pm 0.05$ & $1.88 \pm 0.05$ & $0.51 \pm 0.03$ & $0.81 \pm 0.02$ \\
\hline $\mathrm{C} 20: 3^{\mathrm{b}}$ & & $1.46 \pm 0.13$ & $0.07 \pm 0.01$ & $0.78 \pm 0.04$ & $4.43 \pm 0.58$ & $0.74 \pm 0.04$ & $2.03 \pm 0.04$ \\
\hline $\mathrm{C} 20: 3^{\mathrm{b}}$ & & n.d. & $0.04 \pm 0.01$ & $0.32 \pm 0.02$ & $1.19 \pm 0.62$ & $0.29 \pm 0.02$ & $0.59 \pm 0.02$ \\
\hline C20 : 3 all-cis- $8,11,14$ & $\begin{array}{l}(n \\
-6)\end{array}$ & $3.58 \pm 0.34$ & $0.16 \pm 0.02$ & $3.89 \pm 0.15$ & $17.95 \pm 1.27$ & $0.82 \pm 0.02$ & $3.34 \pm 0.06$ \\
\hline $\mathrm{C} 22: 0$ & & n.d. & $0.07 \pm 0.02$ & n.d. & $1.02 \pm 0.14$ & $0.48 \pm 0.03$ & n.d. \\
\hline C20 : 4 all-cis-5,8,11,14 (AA) ${ }^{\mathrm{f}}$ & $\begin{array}{l}(n \\
-6)\end{array}$ & $337.17 \pm 11.22$ & $17.75 \pm 0.40$ & $61.70 \pm 1.11$ & $505.89 \pm 11.27$ & $67.92 \pm 2.21$ & $104.14 \pm 0.93$ \\
\hline $\mathrm{C} 20: 4^{\mathrm{b}}$ & & n.d. & n.d. & $0.33 \pm 0.03$ & $2.74 \pm 0.13$ & $0.94 \pm 0.04$ & $2.39 \pm 0.05$ \\
\hline C20 : 4 all-cis-8,11,14,17 & & $3.22 \pm 0.25$ & n.d. & $1.78 \pm 0.10$ & $13.23 \pm 0.32$ & $3.84 \pm 0.18$ & $7.53 \pm 0.13$ \\
\hline
\end{tabular}


TABLE 1: Continued.

\begin{tabular}{|c|c|c|c|c|c|c|c|}
\hline \multirow{2}{*}{ Fatty acid } & & \multicolumn{3}{|c|}{ Stipe } & \multicolumn{3}{|c|}{ Blade } \\
\hline & & NL & FFA & PL & NL & FFA & PL \\
\hline & $\begin{array}{l}(n \\
-3)\end{array}$ & & & & & & \\
\hline C20 : 5 all-cis-5,8,11,14,17 (EPA) $)^{\mathrm{g}}$ & $\begin{array}{l}(n \\
-3)\end{array}$ & $79.44 \pm 3.18$ & $2.95 \pm 0.07$ & $30.04 \pm 0.64$ & $397.87 \pm 9.25$ & $82.87 \pm 2.02$ & $250.75 \pm 2.66$ \\
\hline $\mathrm{C} 24: 0$ & & n.d. & $0.36 \pm 0.03$ & n.d. & $0.75 \pm 0.09$ & $1.79 \pm 0.08$ & n.d. \\
\hline C22: 5 all-cis-7,10,13,16,19 & $\begin{array}{l}(n \\
-3)\end{array}$ & $3.20 \pm 0.29$ & $0.19 \pm 0.01$ & $1.26 \pm 0.08$ & $16.33 \pm 0.53$ & $5.48 \pm 0.12$ & $9.12 \pm 0.21$ \\
\hline C22: 6 all-cis-4,7,10,13,16,19 (DHA $)^{\mathrm{h}}$ & $\begin{array}{l}(n \\
-3)\end{array}$ & n.d. & $0.09 \pm 0.02$ & $0.27 \pm 0.05$ & n.d. & $1.84 \pm 0.07$ & $0.18 \pm 0.02$ \\
\hline $\mathrm{C} 26: 0$ & & n.d. & $0.35 \pm 0.03$ & n.d. & n.d. & $1.43 \pm 0.09$ & n.d. \\
\hline Total & & 990.87 & 195.98 & 809.24 & 3604.08 & 937.44 & 1559.49 \\
\hline
\end{tabular}

${ }^{\mathrm{a}}$ Fatty acids are identified by NIST library search only; ${ }^{\mathrm{b}}$ unknown isomer of fatty acid, identified by NIST library search only; ${ }^{\mathrm{c}}$ LA: linoleic acid; ${ }^{\mathrm{d}}$ ALA: alpha linolenic acid; ${ }^{\mathrm{e}} \mathrm{SDA}$ : stearidonic acid; ${ }^{\mathrm{f}} \mathrm{AA}$ : arachidonic acid; ${ }^{\mathrm{g}} \mathrm{EPA}$ : eicosapentaenoic acid; ${ }^{\mathrm{h}} \mathrm{DHA}$ : docosahexaenoic acid; n.d.: not detected. Abbreviations: NL: neutral lipid; FFA: free fatty acid; PL: polar lipid.

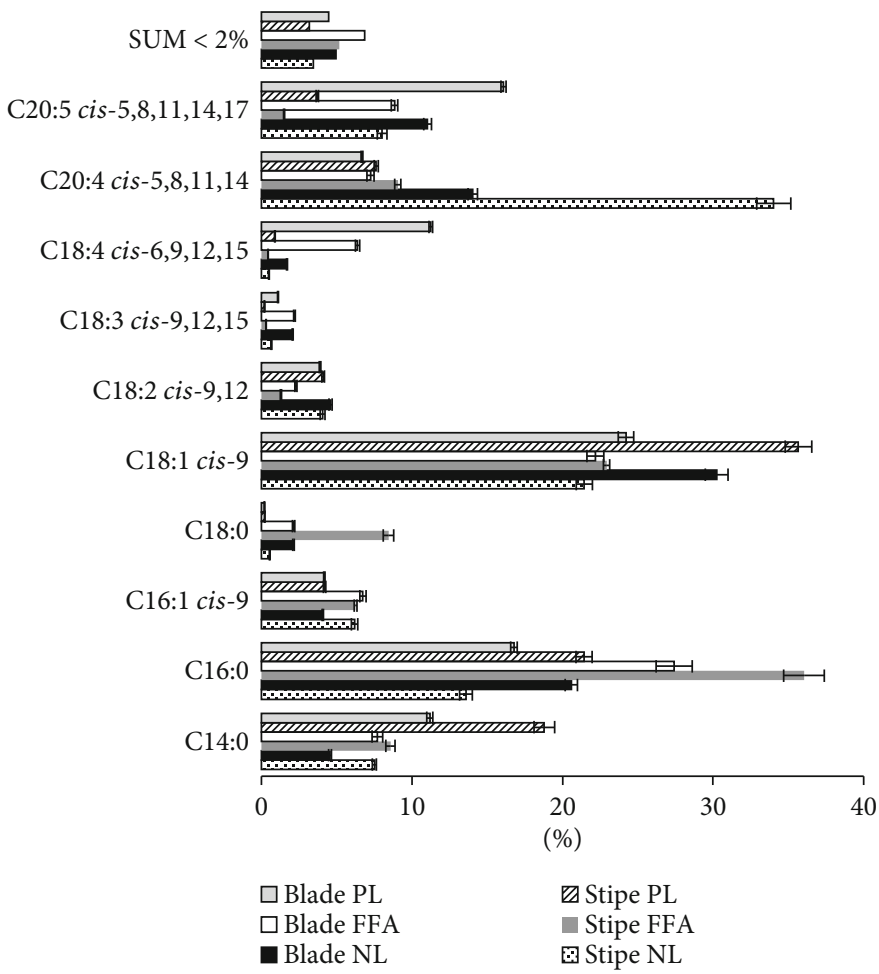

FIGURE 1: Fatty acid profile for fatty acids contributing more than $2 \%$ of the total fatty acid content, in at least one lipid fraction. SUM $<2 \%$ is the summarized contribution of the remaining fatty acids. $(n=4$, two injection parallels for each of these four sample replicates, error bars $= \pm S D)$. NL: neutral lipid; FFA: free fatty acid; PL: polar lipid.

either stipe or blade. All these ten fatty acids corresponded to those identified by others $[7,13,25]$. Schmid and Stengel [25] identified $\mathrm{C} 18: 3 n-6$, at $1.2 \%$ in stipe and $5.5 \%$ in blade, which differs from our results where C18:3n-6 is not above $2 \%$ in any of the blade lipid fractions. This could be due to geographical and/or seasonal variations. The same FA was not detected at all by van Ginneken et al. [13] and also not reported by Maehre et al. [7], who both studied L. hyperborea as one of several macroalgal species. Only a maximum of two trans-fatty acids,
C14:1 trans-9 and C16:2 cis or trans-7,10, were identified in the samples, both in relatively low amounts $(\leq 1.63 \mu \mathrm{g} / \mathrm{g}$ DW $)$. The predominating fatty acids are important dietary $n$ - 3 fatty acids such as $\alpha$-linolenic acid (ALA, C18:3n-3), stearidonic acid (SDA, C18:4n-3), and eicosapentaenoic acid (EPA, C20:5n-3) as well as two $n-6$ fatty acids, linoleic acid (LA, C18:2n-6), and arachidonic acid (AA, C20:4n-6). How favorable L. hyperborea is for the human diet (and thus also in animal feed) and depends on the several factors, for example, content of 
TABLE 2: Sum of SFAs, MUFAs, and PUFAs, as well as $n-6$ and $n-3$ in $L$. hyperborea given in $\mu \mathrm{g} / \mathrm{g} \mathrm{DW},(n=4$, two injection parallels for each sample replicate).

\begin{tabular}{lcccccc}
\hline & & Stipe & & & \multicolumn{2}{c}{ Blade } \\
& NL & FFA & PL & NL & FFA & PL \\
\hline$\sum$ SFA & $224.16 \pm 4.19$ & $109.51 \pm 2.65$ & $330.32 \pm 5.54$ & $1053.05 \pm 14.71$ & $373.81 \pm 11.23$ & $450.16 \pm 3.38$ \\
$\Sigma$ MUFA & $277.83 \pm 5.32$ & $60.70 \pm 0.41$ & $329.40 \pm 7.13$ & $1263.54 \pm 27.19$ & $289.24 \pm 5.25$ & $458.74 \pm 8.00$ \\
$\sum$ PUFA & $488.88 \pm 11.22$ & $25.77 \pm 0.40$ & $149.52 \pm 1.11$ & $1287.49 \pm 11.27$ & $274.39 \pm 2.21$ & $650.58 \pm 2.66$ \\
\hline Total & 990.87 & 195.98 & 809.24 & 3604.08 & 937.44 & 1559.49 \\
\hline$\sum n-3$ & $97.37 \pm 3.18$ & $4.71 \pm 0.07$ & $42.22 \pm 0.64$ & $563.42 \pm 9.25$ & $174.46 \pm 2.02$ & $460.17 \pm 2.66$ \\
$\sum n-6$ & $388.14 \pm 11.22$ & $20.84 \pm 0.40$ & $105.20 \pm 1.11$ & $713.83 \pm 11.27$ & $97.44 \pm 2.21$ & $184.59 \pm 0.93$ \\
$n-6 / n-3$ & 3.99 & 4.43 & 2.49 & 1.27 & 0.56 & 0.40 \\
PUFA/SFA & 2.18 & 0.24 & 0.45 & 1.22 & 0.73 & 1.45 \\
\hline
\end{tabular}

The standard deviations are the highest standard deviation among the summarized values. NL: neutral lipid; FFA: free fatty acid; PL: polar lipid; SFA: saturated fatty acid; MUFA: monounsaturated fatty acid; PUFA: polyunsaturated fatty acid.

essential FAs (LA and ALA), other important nutritional FAs (SDA, AA, EPA), and the ratios between PUFA/SFA and $n-6 / n-3$ fatty acids.

It is known that brown seaweeds grown in temperate or subarctic areas can accumulate $n-3$ and n-6 PUFAs [34]. In both stipe and blade, the lowest amounts of $n-3$ and $n-6$ fatty acids are found in the FFA fraction, while the highest amounts are found in the NL fraction. The highest amounts of the essential FAs, LA, and ALA were found in the NL fraction of blade $(165.5 \mu \mathrm{g} / \mathrm{g} \mathrm{DW}$ and $74.8 \mu \mathrm{g} / \mathrm{g} \mathrm{DW}$, respectively). For stipe, the highest amount of LA and ALA were also found in the NL fraction (40.3 and $6.5 \mu \mathrm{g} / \mathrm{mL} \mathrm{DW}$, respectively). There was a lower proportion of the $n-6 \mathrm{FA}$ arachidonic acid in blade versus stipe (11.1\% and $20.9 \%$, respectively). This corresponds to what was reported by Schmid and Stengel [25].

The World Health Organization (WHO) recommends a daily intake of $0.25 \mathrm{~g} \mathrm{EPA}+\mathrm{C} 22: 6 n-3$ (DHA) as part of a healthy diet [35]. Even though seaweed can have high levels of EPA, the fatty acid DHA is generally absent or only found in small amounts in different phaeophytes [19]. The highest amount of DHA in our study was found in the blade FFA fraction $(1.84 \mu \mathrm{g} / \mathrm{g} \mathrm{DW})$. With a total content of EPA $+\mathrm{DHA}$ in blade at $734 \mu \mathrm{g} / \mathrm{g} \mathrm{DW}$, achieving the recommended amount by consumption of seaweed alone is highly unlikely, as the daily intake would have to be approximately $300 \mathrm{~g}$ dried seaweed (or $1500 \mathrm{~g}$ fresh seaweed). Although $n$ -3 and $n-6$ PUFAs are usually easily oxidized, studies have shown that these PUFAs have exhibited high oxidative stability in seaweed lipids in dried seaweed products [36]. The reason for this might be due to a protective effect of galactosyl and sulfoquinovosyl moieties on PUFAs bonded to glycoglycerolipids (the main membrane lipids) [34].

Stipe and blade differ not only in the content of the individual FAs but also in the amounts of SFAs, MUFAs, and PUFAs (Table 2). The TFA in stipe was distributed evenly between the SFA, MUFA, and PUFA with 33.3\%, 33.5\%, and $33.3 \%$, respectively. The blades, however, had a higher distribution of PUFAs with $36.3 \%$ of TFA and a slightly lower distribution of SFA and MUFA with $30.8 \%$ and $33.0 \%$, respectively. Schmid and Stengel [25] also reported a higher distribution of PUFAs in blade versus stipe with $52.0 \%$ and $32.2 \%$, respectively. The FA distribution differs significantly with geographical and seasonal variations, most likely due to nutrition, light conditions, and other biological factors. van Ginneken et al. [13] found a PUFA distribution of 53\% of TFA in L. hyperborea (fronds) harvested in France with 25\% SFA and 22\% MUFA. Maehre et al. [7] who investigated the same species (whole plant) but harvested from the Norwegian coast reported $34.2 \%$ PUFA, $33.7 \%$ SFA, and $26.5 \%$ MUFA. These results are very similar to our findings, even though there was a significant distance in time of harvest (May/June 2010 versus October 2015). The total amount of PUFAs in blade is 3.3 times higher than in stipe, and the total amounts of SFAs and MUFAs are 2.8 and 3.0 times higher, respectively. PUFAs are preferred over SFAs from a dietary perspective, and replacing SFAs with PUFAs in the diet decrease the risk of coronary heart disease [35]. The NL fraction in stipe and the PL fraction in blade have the highest PUFA/SFA ratio of 2.18 and 1.45, respectively. When combining the lipid fractions, the blade FAs had a higher PUFA/SFA ratio compared to the stipe FAs (1.18 versus $1.00)$.

L. hyperborea has a $n-6 / n-3$ ratio of $0.8 / 1$ in blade and $3.6 / 1$ in stipe. The ratios vary between the lipid fractions, as seen in Table 2, but are higher in stipe than in blade. In Western diet, the $n-6 / n-3$ ratio is $15-20 / 1$, and this is significantly higher than $\sim 1$, which was normal during human evolution $[16,37]$. However, for health benefits, lowering this ratio is considered to be beneficial and associated with prevention of inflammatory, cardiovascular, and neural disorders [13]. $n-6 / n-3$ ratios of $2-5 / 1$ are reported to have suppressive effects on cardiovascular, inflammatory, and autoimmune diseases [16, 38, 39]. Since there is a significant difference between the $n-6 / n-3$ ratios in stipe and blade, using only blade could be considered if a very low $n-6 / n-3$ ratio is desired. Though, in this context, it should also be mentioned that FAO in their 2010 report [35] do not consider this ratio to be important and gives no specific recommendations of such. 


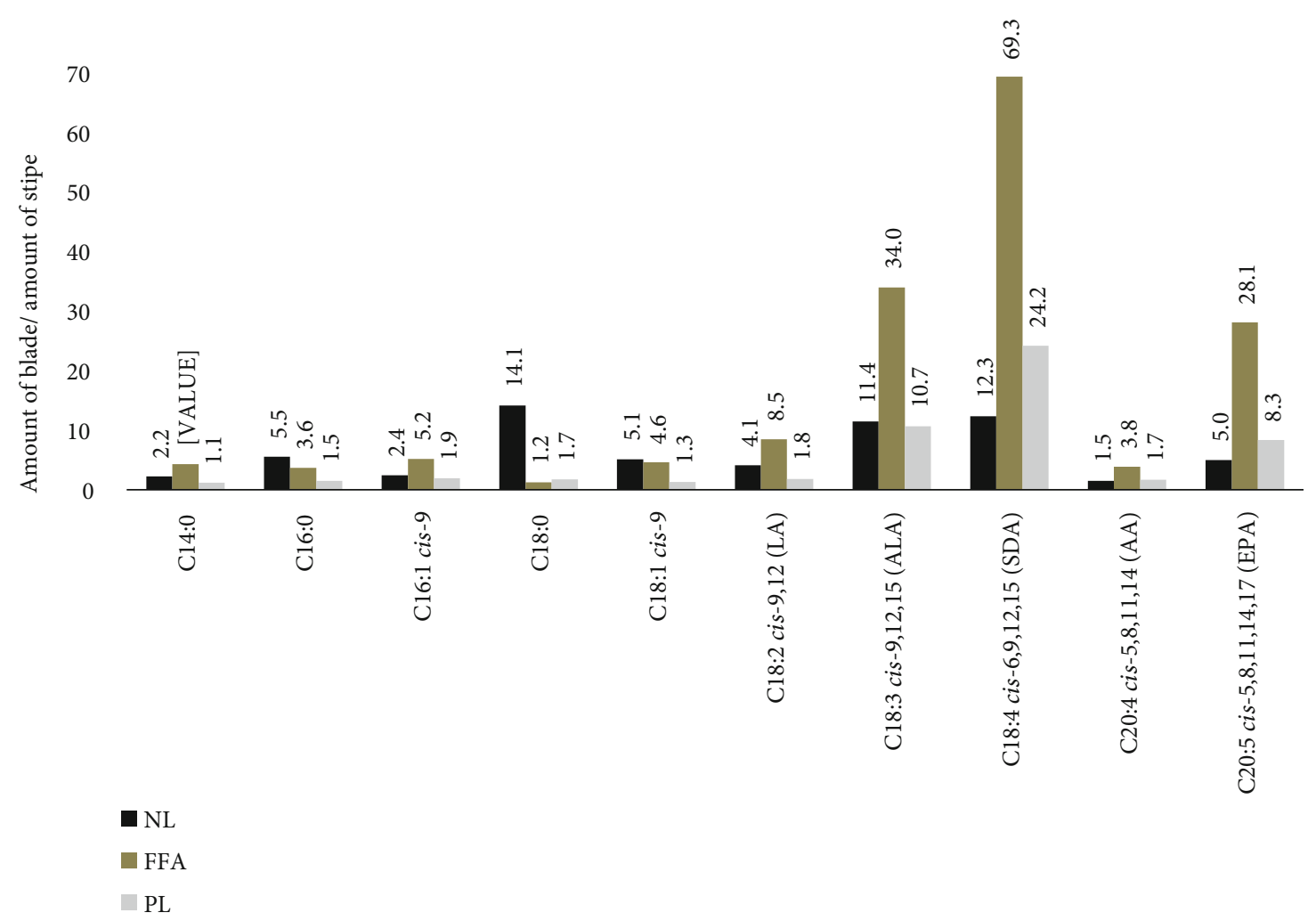

FIGURE 2: Ratio between average blade and stipe amounts in the predominating fatty acids. NL: neutral lipid; FFA: free fatty acid; PL: polar lipid.

While the same fatty acids predominate, the amounts in blade are consistently higher than those in stipe, as seen in Figure 2. This is consistent with results found by Schmid and Stengel [25]. At minimum, the amounts in blade are 1.1 times higher than in stipe for myristic acid (C14:0) in the PL fraction, and at maximum, 69.3 times higher than in stipe for SDA in the FFA fraction. For the FFA and PL fractions, the largest differences are found in the fatty acids ALA, SDA, and EPA. In the NL fraction, the largest difference between stipe and blade amounts is found in stearic acid (C18:0), while blade and stipe amounts are almost equal in the FFA and PL fractions for the same fatty acid.

\section{Conclusions}

A total of 42 different fatty acids are identified and quantified in the stipe and blade of L. hyperborea, with maximum two fatty acids having trans-configuration. Some fatty acids are found either in stipe or blade, while others are only present in certain lipid fractions (NL, FFA, PL) within stipe and blade. Among the predominating fatty acids are the $n-3$ fatty acids ALA (8.8 and $113 \mu \mathrm{g} / \mathrm{g}$ DW), SDA (13.1 and $297 \mu \mathrm{g} / \mathrm{g}$ DW), and EPA (112 and $731 \mu \mathrm{g} / \mathrm{g} \mathrm{DW}$ ), as well as two $n-6$ fatty acids: LA (76 and $248 \mu \mathrm{g} / \mathrm{g}$ DW) and AA (417 and $678 \mu \mathrm{g} / \mathrm{g}$ DW), the values in parenthesis are for stipe and blade, respectively. The ratios between $n-6$ and $n-3$ fatty acids are $\leq 4.4 / 1$ in all lipid fractions but especially low $(\leq 1.3 / 1)$ in blade.
The blades also presented the highest PUFA/SFA ratio. Regarding the potential of commercialization in respect of nutritional applications of L. hyperborea, blade is found to represent the most suitable material, due to higher levels of PUFAs and a low $n-6 / n-3$ ratio.

\section{Conflicts of Interest}

The authors declare they have no conflicts of interest.

\section{Acknowledgments}

The authors would like to thank FMC Biopolymer for sampling the L. hyperborea and Pharmatech AS for milling all samples. The authors would also like to thank the Institute of Marine Research for allowing us to use their picture of a kelp forest in the graphical abstract. This work was supported by the Norwegian University of Life Sciences.

\section{References}

[1] L. Foseid, H. Devle, Y. Stenstrøm, C. F. Naess-Andresen, and D. Ekeberg, "Fatty Acid Profiles of Stipe and Blade from the Norwegian Brown Macroalgae Laminaria hyperborea with Special Reference to Acyl Glycerides, Polar Lipids, and Free Fatty Acids," Journal of Lipids, vol. 2017, Article ID 1029702, 9 pages, 2017.

[2] FAO: Staple foods: What do people eat?, in: Dimensions of Need: An atlas of Food and Agriculture 1995. 
[3] O. K. Chung and J.-B. Ohm, "Cereal lipids," in Handbook of Cereal Science and Technology, K. Kulp and J. G. Ponte, Eds., Marcel Dekker, Inc, 2000.

[4] M. C. Lathman, "Cereals, starchy roots and other mainly carbohydrate foods," Human nutrition in the developing world, 1997.

[5] L. Yu, G. Li, M. Li, F. Xu, T. Beta, and J. Bao, "Genotypic variation in phenolic acids, vitamin $\mathrm{E}$ and fatty acids in whole grain rice," Food Chemistry, vol. 197, no. Part A, pp. 776$782,2016$.

[6] FAO: Fishery Statistical Collections, Global Production; Aqutatic Plants, 2014.

[7] H. K. Maehre, M. K. Malde, K.-E. Eilertsen, and E. O. Elvevoll, "Characterization of protein, lipid and mineral contents in common Norwegian seaweeds and evaluation of their potential as food and feed," Journal of the Science of Food and Agriculture, vol. 94, no. 15, pp. 3281-3290, 2014.

[8] E. M. Brown, P. J. Allsopp, P. J. Magee et al., "Seaweed and human health," Nutrition reviews, vol. 72, no. 3, pp. 205-216, 2014.

[9] N. M. Sanina, S. N. Goncharova, and E. Y. Kostetsky, "Fatty acid composition of individual polar lipid classes from marine macrophytes," Phytochemistry, vol. 65, no. 6, pp. 721-730, 2004.

[10] J. R. Stein and C. A. Borden, "Causive and beneficial algae in human disease conditions: a review," Phycologia, vol. 23, pp. 485-501, 1984.

[11] I. A. Guschina and J. L. Harwood, "Lipids and lipid metabolism in eukaryotic algae," Progress in Lipid Research, vol. 45, pp. 160-186, 2016.

[12] J. L. Harwood and I. A. Guschina, "The versatility of algae and their lipid metabolism," Biochimie, vol. 91, no. 6, pp. 679-684, 2009.

[13] V. J. T. van Ginneken, J. P. F. G. Helsper, W. de Visser, H. van Keulen, and W. A. Brandenburg, "Polyunsaturated fatty acids in various macroalgal species from North Atlantic and tropical seas," Lipids in Health and Disease, vol. 10, no. 1, pp. 104-104, 2011.

[14] A. J. Harborn, Phytochemical methods a guide to modern techniques of plant analysis, Springer, 1998.

[15] L. Mišurcová, "Chemical Composition of Seaweeds," in Handbook of Marine Macroalgae, Biotechnology and Applied Phycology, S.-K. Kim, Ed., Wiley-Blackwell, 2012.

[16] A. P. Simopoulos, "The importance of the ratio of omega6/omega-3 essential fatty acids," Biomedicine \& Pharmacotherapy, vol. 56, no. 8, pp. 365-379, 2002.

[17] G. A. Fariman, S. J. Shastan, and M. M. Zahedi, "Seasonal variation of total lipid, fatty acids, fucoxanthin content, and antioxidant properties of two tropical brown algae (Nizamuddinia zanardinii and Cystoseira indica) from Iran," Journal of Applied Phycology, vol. 28, no. 2, pp. 1323-1331, 2016.

[18] R. F. Patarra, J. Leite, R. Pereira, J. Baptista, and A. I. Neto, "Fatty acid composition of selected macrophytes," Natural Product Research, vol. 27, no. 7, pp. 665-669, 2013.

[19] H. Pereira, L. Barreira, F. Figueiredo et al., "Polyunsaturated fatty acids of marine macroalgae: potential for nutritional and pharmaceutical applications," Marine Drugs, vol. 10, no. 12, pp. 1920-1935, 2012.

[20] D. I. Sánchez-Machado, J. López-Cervantes, J. López-Hernández, and P. Paseiro-Losada, "Fatty acids, total lipid, protein and ash contents of processed edible seaweeds," Food Chemistry, vol. 85, no. 3, pp. 439-444, 2004.

[21] G. Silva, R. B. Pereira, P. Valentão, P. B. Andrade, and C. Sousa, "Distinct fatty acid profile of ten brown macroalgae," Revista Brasileira de Farmacognosia, vol. 23, no. 4, pp. 608613, 2013.

[22] C. Dawczynski, R. Schubert, and G. Jahreis, "Amino acids, fatty acids, and dietary fibre in edible seaweed products," Food Chemistry, vol. 103, no. 3, pp. 891-899, 2007.

[23] D. Rodrigues, A. C. Freitas, L. Pereira et al., "Chemical composition of red, brown and green macroalgae from Buarcos bay in central west coast of Portugal," Food Chemistry, vol. 183, pp. 197-207, 2015.

[24] S. V. Khotimchenko, "Fatty acids of brown algae from the Russian far east," Phytochemistry, vol. 49, no. 8, pp. 2363-2369, 1998.

[25] M. Schmid and D. B. Stengel, "Intra-thallus differentiation of fatty acid and pigment profiles in some temperate Fucales and Laminariales," Journal of Phycology, vol. 51, no. 1, pp. 25-36, 2015.

[26] B. J. Gosch, N. A. Paul, R. de Nys, and M. Magnusson, "Seasonal and within-plant variation in fatty acid content and composition in the brown seaweed Spatoglossum macrodontum (Dictyotales, Phaeophyceae)," Journal of Applied Phycology, vol. 27, no. 1, pp. 387-398, 2015.

[27] J. Folch, M. Lees, and G. H. S. Stanley, "A simple method for the isolation and purification of total lipides from animal tissues," The Journal of Biological Chemistry, vol. 226, no. 1, pp. 497-509, 1957.

[28] H. C. Pinkart, R. Devereux, and P. J. Chapman, "Rapid separation of microbial lipids using solid phase extraction columns," Journal of Microbiological Methods, vol. 34, no. 1, pp. 9-15, 1998.

[29] J. Ruiz, T. Antequera, A. I. Andres, M. J. Petron, and E. Muriel, "Improvement of a solid phase extraction method for analysis of lipid fractions in muscle foods," Analytica Chimica Acta, vol. 520, no. 1-2, pp. 201-205, 2004.

[30] H. Devle, E.-O. Rukke, C. F. Naess-Andresen, and D. Ekeberg, "A GC-magnetic sector MS method for identification and quantification of fatty acids in ewe milk by different acquisition modes," Journal of Separation Science, vol. 32, no. 21, pp. 3738-3745, 2009.

[31] D. B. Stengel, S. Connan, and Z. A. Popper, "Algal chemodiversity and bioactivity: sources of natural variability and implications for commercial application," Biotechnology Advances, vol. 29, no. 5, pp. 483-501, 2011.

[32] J. V. Vilg, G. M. Nylund, T. Werner et al., "Seasonal and spatial variation in biochemical composition of Saccharina latissima during a potential harvesting season for Western Sweden," Botanica marina, vol. 58, pp. 435-447, 2015.

[33] B. J. Gosch, M. Magnusson, N. A. Paul, and R. de Nys, “Total lipid and fatty acid composition of seaweeds for the selection of species for oil-based biofuel and bioproducts," GCB Bioenergy, vol. 4, no. 6, pp. 919-930, 2012.

[34] K. Miyashita, N. Mikami, and M. Hosokawa, "Chemical and nutritional characteristics of brown seaweed lipids: a review," Journal of Functional Foods, vol. 5, pp. 1501-1517, 2013.

[35] Food and Agriculture Organization, Fats and fatty acids in human nutrition - Report of an expert consultation, FAO Food and Nutrition Paper 91, 2010.

[36] R. Sugimura, M. Suda, A. Sho et al., "Stability of fucoxanthin in dried Undaria pinnatifida (Wakame) and baked products 
(Scones) containing Wakame powder," Food Science and Technology Research, vol. 18, no. 5, pp. 687-693, 2012.

[37] A. P. Simopoulos, "An increase in the Omega-6/Omega-3 fatty acid ratio increases the risk for obesity," Nutrients, vol. 8, no. 3 , p. 128, 2016.

[38] G. L. Russo, "Dietary n-6 and n-3 polyunsaturated fatty acids: from biochemistry to clinical implications in cardiovascular prevention," Biochemical Pharmacology, vol. 77, no. 6, pp. 937-946, 2009.

[39] P. M. Kris-Etherton, D. S. Taylor, S. Yu-Poth et al., "Polyunsaturated fatty acids in the food chain in the United States," The American Journal of Clinical Nutrition, vol. 71, no. 1, pp. 179S-188S, 2000. 